TURIZAM

Volume 15 , Issue 4

159-168 (2011)

\title{
Influence of Age and Educational Level on the Behavior of Hunters in Vojvodina Province (Serbia)
}

Vladimir Marković ${ }^{\star}$, Nemanja Davidović*, Branislav Djurdjev*, Aleksandra Dragin *

Received: September 2011 | Accepted: November 2011

\begin{abstract}
Education as an important factor in the development of economy has a major impact on the development of hunting and hunting tourism. In this research, it has conducted a survey of hunters from the territory of Vojvodina Province regarding their attitude and motives for hunting, importance of education, importance of GIS in hunting, poaching as well as their level of hunting ethics. Using SPSS program, it was cross-referenced the individual responses in relation to age category and level of education. The results show that the youngest hunters (18 to 35 years) compared to middle age hunters (35-59 years) and old hunters (over 60) visit hunting events more, they are the most informed about GIS and they are most willing to learn about these technologies. The number of hunters that took part in the poaching is proportional with their level of education, so that most hunters that participate in poaching hold a university degree. However, hunters holding a university degree in the highest percentage believe that GIS can contribute to the development of hunting largely, and are willing to participate in training.
\end{abstract}

Key words: education, hunting, GIS, Vojvodina Province

\section{Introduction}

Hunting and fishing are important traditional tourism products of Vojvodina Province. Hunting grounds in Vojvodina Province represent important economic and tourism potential for the province. Potential hunting destinations, such as Vojvodina Province, should launch themselves into highly competitive international markets by offering professional services and more educated hunting organization officials, hunter professionals and hunters (Mulec, 2OIO). Numerous big game trophies, several state champions, and a few world champions show exceptional quality of hunting grounds. Concerning the small game and migratory birds, based on the bagged number, it can be said that Vojvodina Province belongs

\footnotetext{
* University of Novi Sad, Faculty of Sciences, Department of Geography, Tourism and Hotel Management, Trg
} Dositeja Obradovića 3, Novi Sad, corresponding author: vladimir.markovic@dgt.uns.ac.rs 
among the top places in Europe. In the period from 1979 to 2000, hunting organizations made a profit of I8 million Euros from selling trophies and meat. In addition, there is a profit from charging foreign hunters for logging and other services (7.5 million Euros). Majority of the profit is generated from pheasants, turtledoves, bucks, hares, quails and other game. As new forms of special interest tourism are developed and continue to expand (MacKay, 20O2; Zeppel, Hall, I99I) more traditional tourism products, such as fishing and hunting maybe perceived in a different light. Effective management of hunting resources requires knowledge of the current regulations and the effects of regulations on the sustainability of wild populations (Angulo, Villafuerte, 2003). As hunting in particular is an activity that has come under increasing attacks by anti-hunting groups, it is very important to react on the education of hunters. Education of hunters contributes to better relationship between wildlife and hunters, and thus contributes to more rational use of this semi-renewable natural resource. Most research has focused on hunters' motivations and attitudes (Decker, Connely, I989). In addition, many researchers have also focused on factors affecting participation in hunting (Riley et al., 2003). Some surveys in USA have examined initiation of behavior, hunter motivations and satisfaction (Hammitt et al., 1990), and ethics (Kuentzel, Heberlein, 1992). The primary purpose of this paper is to examine average age of hunters, average length of the hunting experience, hunting motives, level of education, topics of interest for education, attitudes about the hunting ethics and poaching. In addition, the subject of the survey is to research attitudes and the level of information related to GIS, which can provide important information for decision making in hunting management as a mean important for the development and enhancement of hunting in Vojvodina Province (Marković, Stankov, 2OIO). Using GIS, potential users of hunting-tourism services, provides better insight into the hunting-tourism product, and the ability to create hunting-tourism arrangements on they own wishes and possibilities (Marković, Prentović, 2OIO). The aim of the survey is to identify differences in the attitudes of hunters, about the application of GIS in hunting, about poaching and about education, based on age groups differences in education among hunters. The task is to analyze, compare and structure the attitudes of different categories of hunters.

\section{Materials and methods}

\section{Study area}

This research was conducted in Vojvodina Province, Serbia, during 2OIO. The study area encompasses 2,I52,625 hectares (Antonić, Beuković, 2007) of hunting ground and 24,00O hunters (Marković, 2OIO) in 57 hunting associations. All official hunting associations in the Vojvodina Province annually report the condition of game to the Hunting Association of Vojvodina Province and Statistical Office of the Republic of Serbia. However, hunting associations are not required to provide information about their hunters, their level of educations or even age. For this reason, this survey was conducted on hunters in six hunting associations on the principle of territorial equality, so that the research had two hunting associations from Backa, Banat and Srem subregions. 


\section{Data collection}

Data collection techniques are based on a prepared questionnaire and a specific sample. For the purposes of this paper, deliberately patterned on the principle of anonymity, I35 hunters filled a survey (I8.5\% from the Hunting Association Sonta, I6.3\% from the Hunting Association Bački Jarak, I6.3\% from the Hunting Association Novi Kneževac, I6.3\% from the Hunting Association Čerević, I6.3\% from the Hunting Association Novi Kozarci, and I6.3\% from the Hunting Association Ruma.

\section{Results and discussion}

Average age of hunters. The survey participants were hunters of all age groups (in total I35 hunters). The youngest hunter is 20 and the oldest 87 years, and the average age of hunters was 47.58 years.

Dragin et al. (2006) found that the average age of hunters in Western Backa region (a part of Vojvodina Province) being 43.8 in I98I, and about 49.4 in 2002. It can be concluded that the average age of hunters in Vojvodina in the last decade is being reduced, i.e. that the hunting population is rejuvenated for I.82 years.

Hunting experience. Some hunters were engaged in hunting relatively recently - two years ago, while some hunters have had hunting experience as long as 52 years. Average engage in hunting activities is 22.16 years.

Level of education. Of the total number of hunters, 9.6\% had primary school education, while the most of them had high school education $63.7 \%$. The college education is represented by I6.3\% and IO.4\% holds a university diploma.

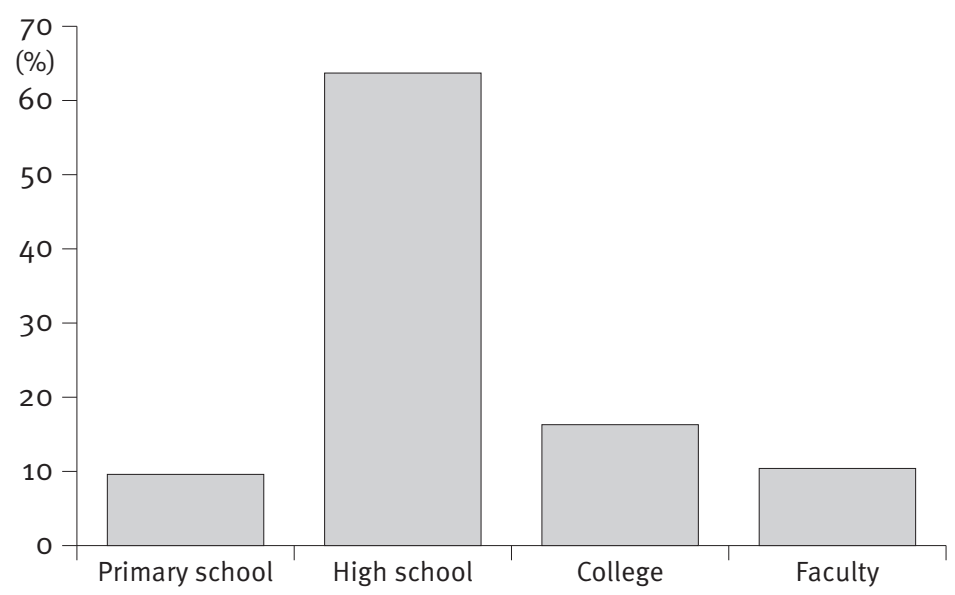

Figure 1 Level of educations in hunting populations

Source: own elaboration

Motivation. As the primary motive for engaging in hunting, 46.7\% marked liking with nature, and the $34.1 \%$ of hunters marked socializing with other hunters. Family tradition as a primary motive was marked by $\mathrm{I} 8.5 \%$ of hunters, while the least of hunters $0.7 \%$ claimed that benefit from catch is primary motive for engaging in hunting. 


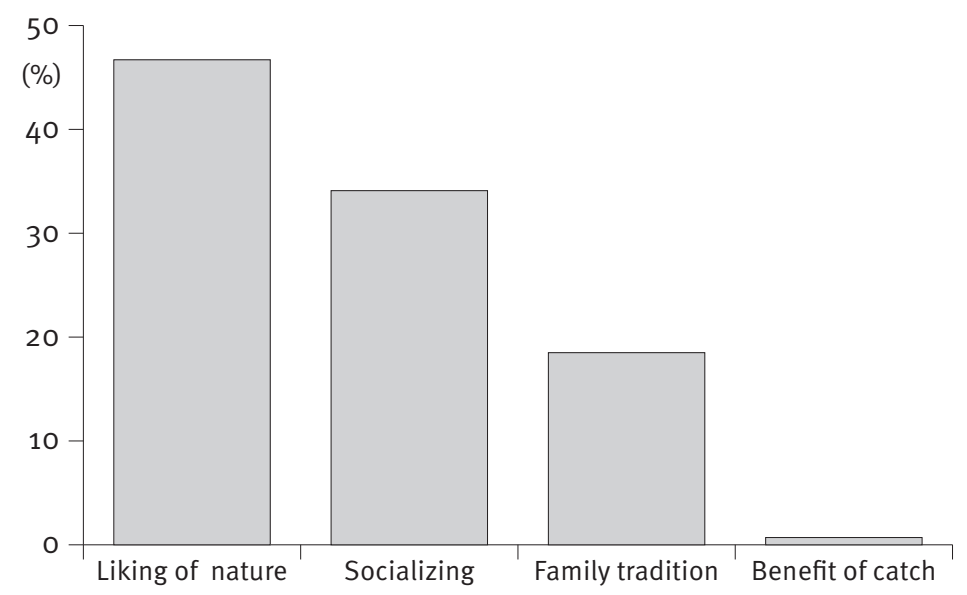

Figure 2 Primary motive for engaging in hunting

Source: own elaboration

Fields of education. Generally, most hunters or $77.6 \%$ of them are interested in education in the field of hunting, while 22.2 are not.

In the field of education, most hunters are shown interest for cynology (54.8\%), followed by the hunting legislation (37\%), game biology (36.3\%), hunting tourism (33.3\%), while the least demonstrated interest in education is in the field of breeding and protection of game - only $5.2 \%$ of hunters. Only in the field of cinology, percentages of those who want education are above those who do not want it. In the field of game biology, hunting legislation and hunting tourism, the percentage of those who do not want education is almost more than twice higher of those who want. The most unfavorable situation is in the field of breeding and protection of game, because the number of those who do not want education is I9 times higher than those who want.

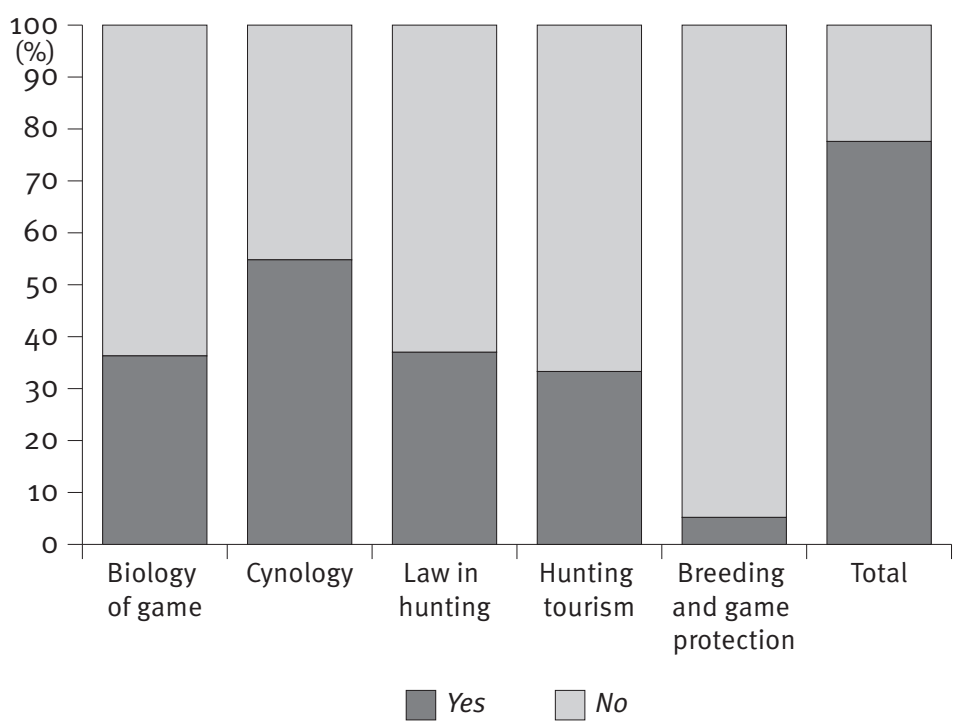

Figure 3 Fields of educations

Source: own elaboration 


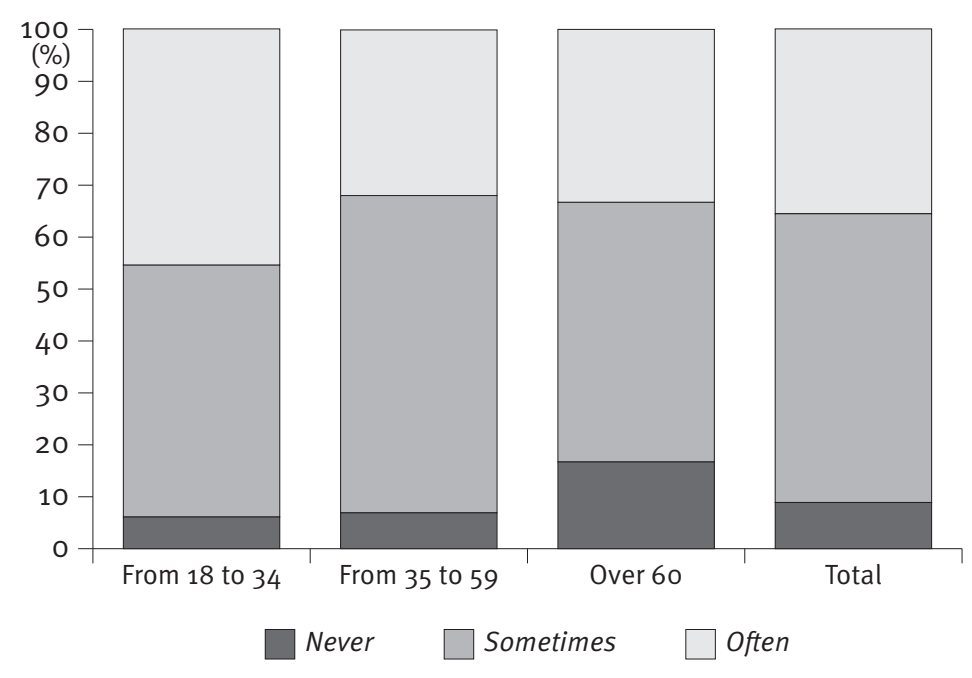

Figure 4 Visiting hunting events

Source: own elaboration

Hunting events and manifestations. When asked if and how often do they visit hunting events or manifestations, $8.9 \%$ of the respondents answered negatively, while $55.6 \%$ of hunters sometimes visited events of this type, and $35.6 \%$ of them visit hunting events regularly.

Considered by age structure of hunters, interesting observations can be made. The average percentage of hunters who never attend the events or manifestation is $8.9 \%$. By age groups, the highest ratio is among hunters over the age of 60 (I6.7\%), while hunters from 35 to 59 years are represented with $6.9 \%$ in this group. The youngest age group makes up the smallest amount with. 6.I\%. This data shows that hunters older than 60 years are least likely to visit the events or manifestations of this type. On the other hand, the youngest age group of hunters (I8 to 34 years) are most likely to visit these events and manifestations, (45.5\% of respondents in this group responded that they often visit events), while this percentage at the hunters middle age group was 3I, 9\% and for hunters over 60 years of $33.3 \%$.

Knowledge of GIS. When asked if they knew what the GIS is, the highest percentage of hunters, 54.I\% of them responded negatively. More than third of hunters (38.5\%) answered that they know what GIS is, but did not use it, while 7.4\% said they have used GIS.

In relation to age structure, the youngest hunters are most familiar with GIS, while the oldest are hunters with the least knowledge of GIS.

The evaluation of GIS contribution to hunting depends on hunter's age structure. The largest number of respondents, $60.7 \%$ answered that they do not know whether the application of GIS helped the development and enhancement of hunting. 25.2\% of hunters consider its contribution to a greater extent, and I4.I\% of them to a small extent.

As with previous questions, the responses among different ages are quite different. GIS apply helped the development of hunting to a large extent is considered by $33 \%$ of hunters aged I 8 to $34,22.2 \%$ of hunters aged 35 to 59 years, and $23.3 \%$ of older hunters. The hunters who do not know the answer to this question, are least represented in the youngest group $54.5 \%$, while the most represented are older than 6 o years, $66.7 \%$ of them. Based on analysis of responses, it can be concluded that the youngest are most informed about the importance of applying GIS in hunting, as opposed to hunters who belong to the oldest group. 


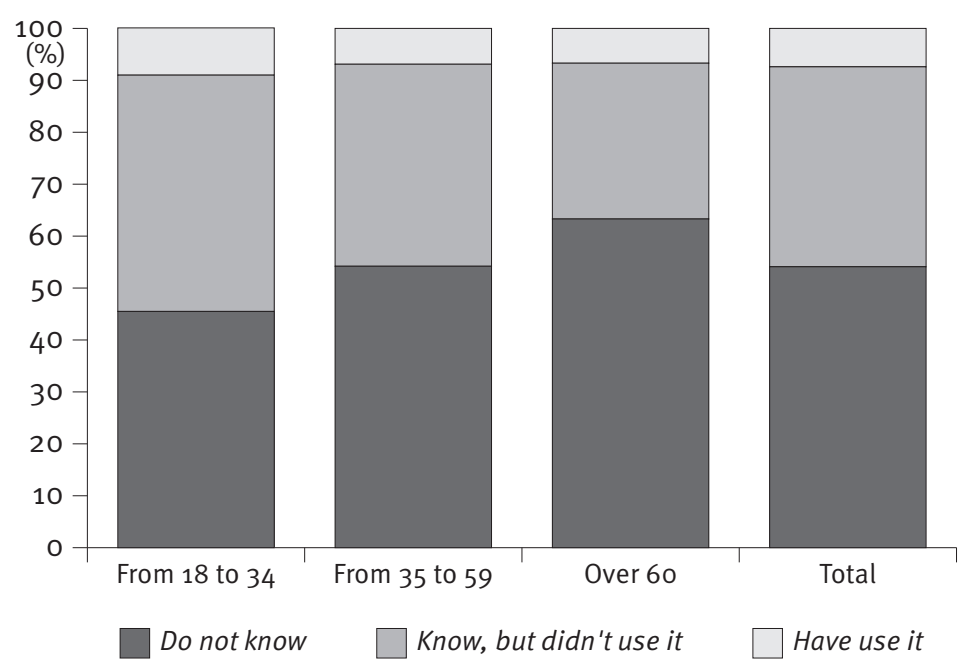

Figure 5 Knowledge of GIS

Source: own elaboration

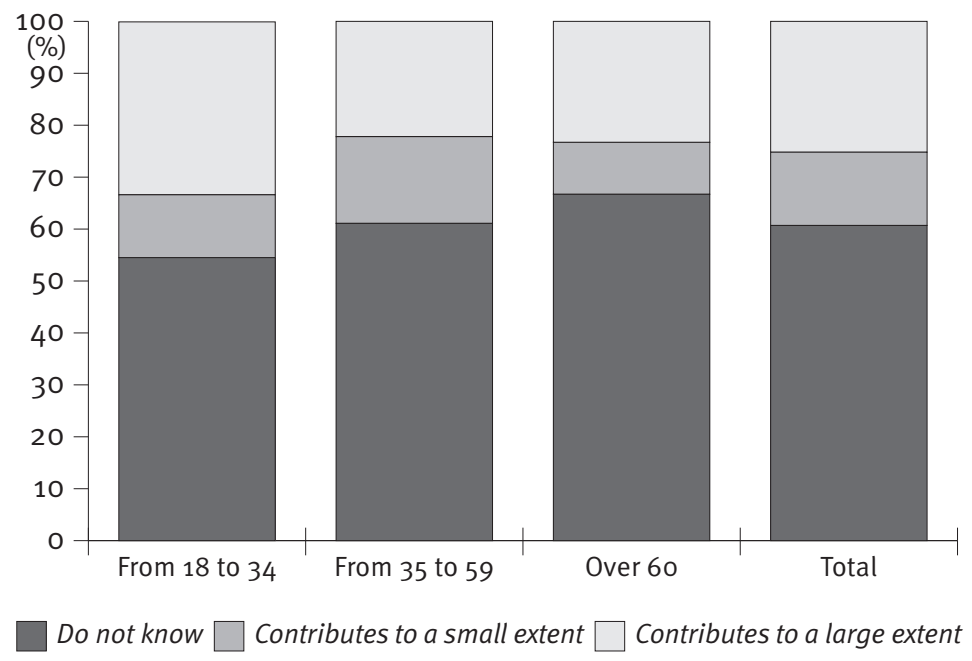

Figure 6 Does GIS contributes to hunting (hunters' age structure)

Source: own elaboration

In relation to hunters' level of education, the highest percentage of hunters who believe that GIS can contribute largely to the development of hunting, are hunters with higher level of education (42.9\%), while the lowest percentage makes hunters with primary school education (I5.4\%). Hunters with faculty level of education also make the highest percentage of hunters who think that GIS can contribute also to a small extent (2I.4\%), while the lowest percentage makes hunters with primary school education (7.7\%). Based on analysis of responses, it can be concluded that the hunters with the highest level of education are most informed about the importance of applying GIS in hunting, as opposed to hunters who have the elementary school certificate as the highest level of education. 


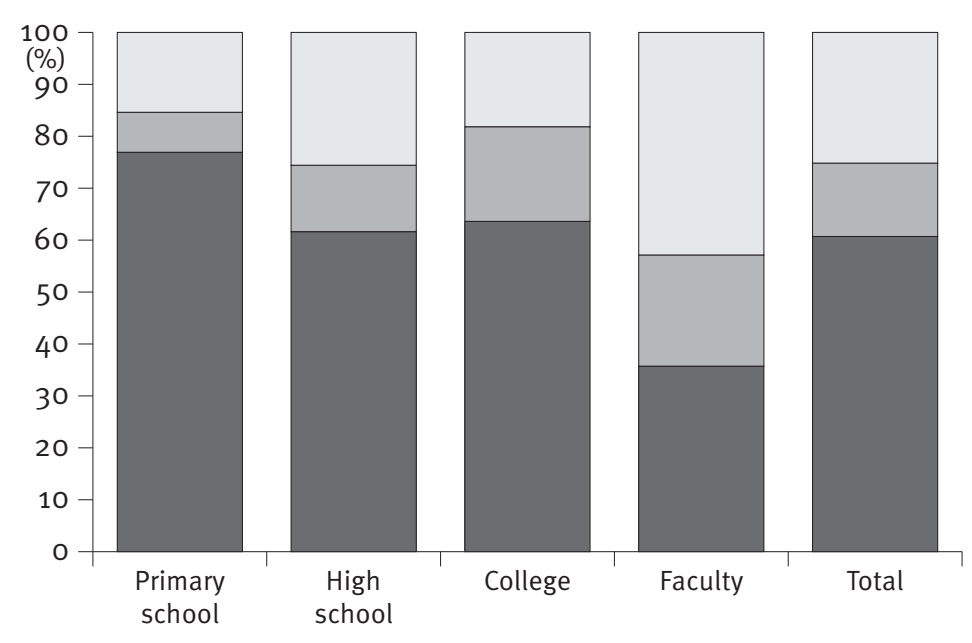

Do not know $\square$ Contributes to a small extent $\square$ Contributes to a large extent

Figure 7. Does GIS contributes to hunting (hunters'level of education) Source: own elaboration

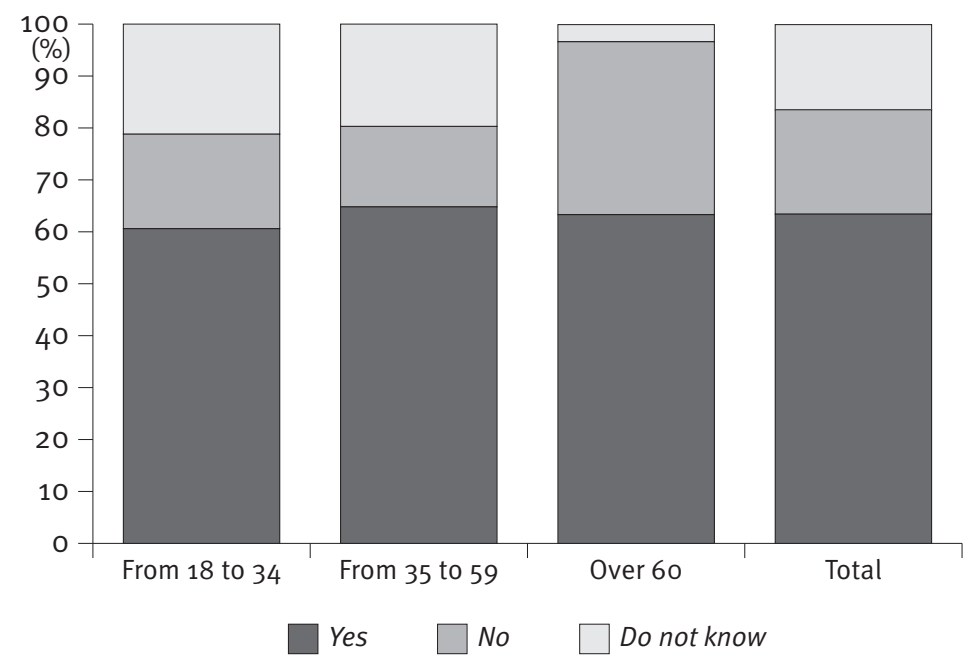

Figure 8. Training to use GIS technologies (hunters' age structure)

Source: own elaboration

When asked if they are interested in training to use these technologies, $63.4 \%$ answered positively, $\mathrm{I} 6.4 \%$ did not know, and 20.I\% answered negatively.

Comparing the percentages among the age groups, in terms of positive response, no age group is particularly distinctive and all age groups are equally interested in education. Hunters interested in education, according to the age group, are as follows: $60.6 \%$ young hunters, $64.8 \%$ middle age, and $63.3 \%$ in the oldest group of hunters. However, a negative answer was given by $33.3 \%$ of hunters from the oldest group, while the percentage of young hunters was $\mathrm{I} 8.2 \%$ and $\mathrm{I} 5.5 \%$ of middle age hunters. There is a greater uncertainty and indecision among younger (2I.2\%) and middle age hunters (19.7\%). 


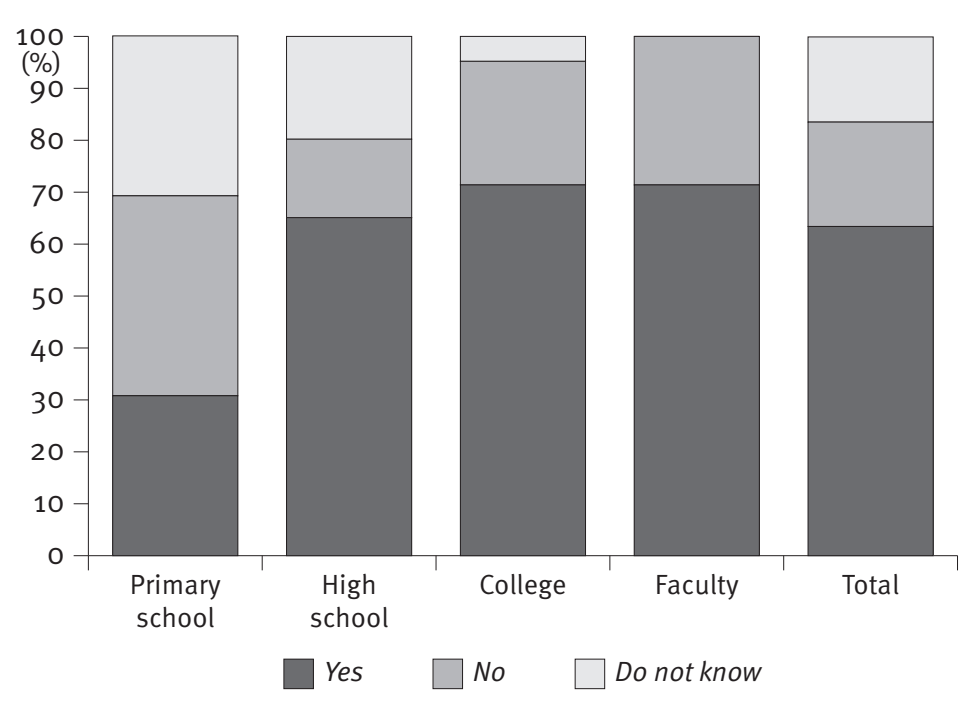

Figure 9 Training to use GIS technologies (qualifications)

Source: own elaboration

By qualification, the percentage of those who are interested in training is growing in line with level of education. Therefore, the highest percentage of hunters interested in training makes hunters with faculty diploma and college (7I.4\%), then hunters with high school (65.I\%), while the lowest percentage makes hunters with primary school education (30.8\%).

Participation in poaching. According to the survey, remarkable $70.4 \%$ of hunters said they had never participated in poaching, I7.8\% of them said that they happened once, and II. $8 \%$ of them that happened to them several times.

If analyze the responses in which hunters admit that they took part in poaching several times, compared to the level of educations the following results are obtained. The largest per-

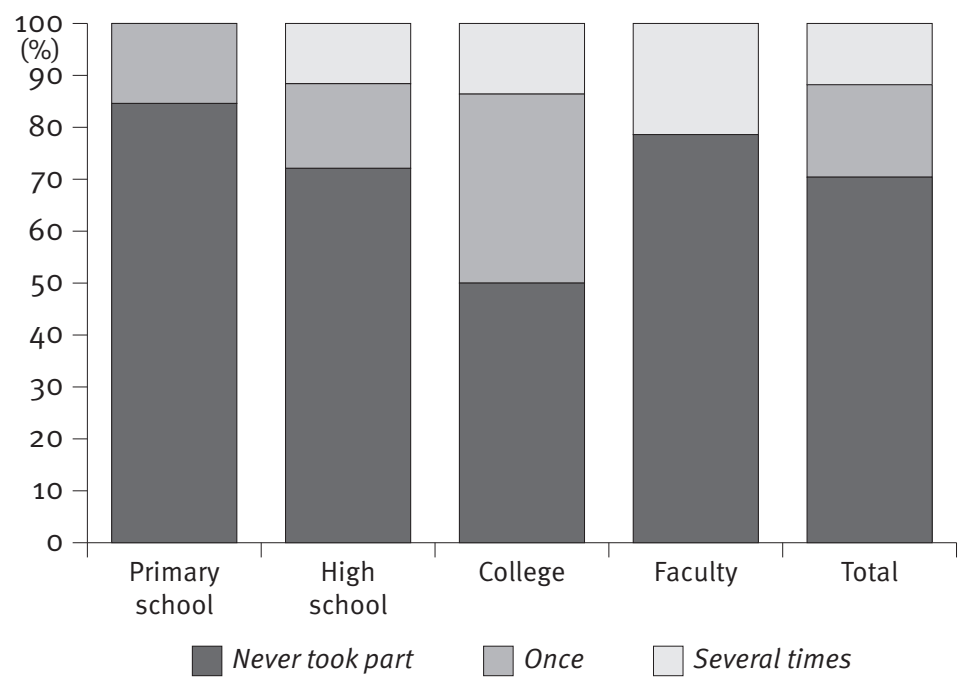

Figure 10 Participation in poaching

Source: own elaboration 
centages, even $2 \mathrm{I} .4 \%$ of respondents are hunters with faculty education. Hunters with college consist $\mathrm{I3} .6 \%$, and high-educated hunters II.6\%. It is interesting that among the hunters who have primary education nobody responded with this answer. In addition, this group represents the highest percentage of hunters who had never participated in poaching - $84.6 \%$ of them. This information shows that the hunting ethics and morality are at the highest level among hunters with the lowest level of education, and probably with the lowest incomes. It can be considered that the penalty is one of the important factors affecting the decreased proportion of poaching in this group.

\section{Conclusion}

In many countries, some surveys have examined initiation of behavior, motivations, satisfaction and ethics of hunters. This paper represent one of the rarely researches among hunters in Vojvodina Province. Results show average length of the hunting experience, hunting motives, level of education, topics of interest for education, attitudes and the level of information related to GIS, attitudes about the hunting ethics and poaching, in relation to age category and level of education. In addition, the results show that the most numerous hunters in Vojvodina Province are high school educated hunters from middle age group, which are not so interested in education like younger or more educated hunters.

Although a percentage of hunters, whose main motive for hunting represent benefit from the catch, is insignificant, poaching (which is based on benefit from the catch) represent a major problem in hunting in Vojvodina, because it is still widespread among hunters. Therefore, it is necessary to involve more middle age and the oldest group of hunters in hunting events and trends, and to reduce poaching in Vojvodina Province by improving knowledge of hunters. This study can be considered as a useful information and guidance for hunting related decisions. In other words, the results are valuable for hunting organization officials, hunter professionals and hunters.

\section{Acknowledgment}

This paper is part of the project No. II4-45I-I86I/2OII-O2 financed by the Provincial Secretariat for Science and Technological Development of the Vojvodina Province, Serbia.

\section{References}

Antonić, N., Beuković, M. (2007). Hunting Organization of Vojvodina, Hunting Association of Vojvodina, Novi Sad.

Angulo, E., Villafuerte, R. 2003. Modeling hunting strategies for the conservation of wild rabbit populations, Biological Conservation II5, 29I-3OI.

Decker, D. J., Connely, N. A. I989. Motivations for deer hunting: implications for antlerless deer harvest as a management tool, Wildlife Society Bulletin I7, 455-463.

Dragin, A., Bubalo-Živković, M., Đurdev, B. 2006. Population aging: case study of hunters in western Bačka region, Collection of the Papers of Faculty of Geography, University of Belgrade, vol. LIV, 97-II4. 
Hammitt, W.E., McDonald, C. D., Patterson, M.E. I990. Determinants of multiple satisfaction for deer hunting, Wildlife Society Bulletin 8, 33I-337.

Kuentzel, W., Heberlein, T.A. I992. Does specialization affect behavioral choices and quality judgments among hunters?, Leisure Sciences I4, 2II-226.

MacKay, K. 20O2. Identification of key influences on heritage tourism activity participation, Journal of the Canadian Association for Leisure Studies, 26(I, 2), 3-28.

Marković, V. (2OIO). Application of geographic information technologies in hunting tourism in Vojvodina, PhD thesis, Novi Sad.

Marković, V., Prentović, R. 2OIO. Aplication of information technologies in propaganda of hunting tourism of Vojvodina, Abstract book ,Tourist image of Serbia as a factor of the development of economy“, 56.

Marković, V., Stankov, U. 2OIO. Reducing negative flood impacts in „Apatinski rit“ part of Special nature reserve „Gornje pondunavlje“ (Vojvodina, Serbia) using GIS. Geographica Panonnica Vol I4, No 2, 4I-48.

Mulec, I. 2OIO. Promotion as a tool in sustaining the destination marketing activities, Turizam, Vol I4, issue I, I3-2I.

Riley, S.J., Decker, D.J., Enck, J.W., P.D., Curtis, T.B., Lauber, T.L., Brown. 2003. Deer populations up, hunter population down: implications of interdependence of deer and hunter population dynamics of management, Ecoscience IO, 455-46I.

Zeppel, H., Hall, M. I99I. Selling art and history: Cultural heritage and tourism, Journal of Tourism Studies, 2(I), 29-45. 